\title{
ANALYSIS ON THE MSW THERMAL DEGRADATION PROCESSES
}

\author{
C. MARCULESCU ${ }^{1 *}$ \\ G. ANTONINI ${ }^{2}$ \\ A. BADEA ${ }^{1}$
}

\author{
${ }^{1}$ Department of Power Engineering \\ University POLITEHNICA of Bucharest \\ 313, Splaiul Independentei \\ sector 6, Bucharest, Romania \\ ${ }^{2}$ Department of Industrial Methods \\ University of Technology Compiègne \\ BP20529 60205 cedex, France
}

Received: $24 / 11 / 05$

Accepted: 29/03/06 *to whom all correspondence should be addressed: e-mail: cosmin@fiab.pub.ro

\section{ABSTRACT}

The waste to renewable energy source has become a priority in the wastes treatment field. The research goal is not only the wastes destruction but also a better thermal energy recovery from the processes. The municipal solid waste presents a high heterogeneity degree from the dimensional point of view, form and its components specific weight of as well as thermal-chemical characteristics. That's why there are many treatment methods, each one with its own particularities.

For a better understanding of the phenomenon during thermal degradation processes both under pyrolysis or atmospheric pressure gasification stages we first accomplished a laboratory scale series of experiments in a tubular reactor, on small quantities ( $5-10$ grams) of reconstituted urban wastes. For the validation of the obtained data on more representative samples we extended the experiment to an original industrial scale pilot installation that enables the continuous thermal treatment of $10-50$ waste kilograms per hour under oxidant or non-oxidant atmosphere (on choice) and at variable temperature between $400{ }^{\circ} \mathrm{C}-1100{ }^{\circ} \mathrm{C}$. The residential time of the treated sample in the installation and the flow conditions can be set independently. The installation reproduces the incinerators or the pyrolysis / gasification reactor process conditions and provides complete information on the wastes thermal degradation kinetics and on the pollutant emissions. The particularity of the device consists in the product advancing piston - like flow system based on the bed vibration. The product particles in the bed have a translation movement without any layer shift. Therefore the particles distribution in a given product bed section is the same all along the installation from the feeding inlet to the extraction. That characteristic enables us to extrapolate and compare the laboratory results of the fixed bed treatment to the industrial pilot continuously treatment applied on the same product: reconstituted municipal solid waste, one of the most heterogynous solid wastes in mixture.

The main targets were the sample mass reduction rate, the resulting gases composition, the samples mechanical behavior for different temperature levels, residential time, treatment atmosphere conditions and different steam flow rates (in the gasification process). The results were compared to an established reference - the incineration.

The paper presents the research and results on the degradation mechanisms of MSW treated samples in those two equipments from the Science Division CNRS, Department of Industrial Methods, University of Technology Compiègne, France.

KEYWORDS: MSW, thermal treatment, incineration, pyrolysis, gasification, pollutant gases, mass reduction rate. 


\section{INTRODUCTION}

The waste to energy field encountered in the last decade many transformations as process approach and available technology. The well-known "incineration" lost many specialists and public support due to several unexpected severe effects from the environmental and health risk point of view such as the presence of dioxins in the outgoing gases streams. In addition to that, the new international policy on the $\mathrm{CO}_{2}$ emissions forced the industrials from the wastes treatment field to turn to the alternative processes of pyrolysis and gasification. These methods well known in the past (the coal from wood and fuel gas for the war effort in the second WW) were more or less minimized after 1950. Due to their undeniable advantages compared to incineration concerning especially the $\mathrm{CO}_{2} /$ treated waste rate and the absence of dioxins, they are the alternative for a safer waste thermal treatment in spite of many green organization, unaware of the process characteristics and ruled by the NIMBY concept. Nevertheless, the long period of research inactivity on those two technologies, as well as the increasing variety of wastes, are at the base of the technology delay compared to this field dynamic.

The option for a certain treatment method requires the knowledge of as many physicalchemical characteristics of the waste to be treated as possible together with the process kinetics [1]. The only existing tests for those characteristics diagnosis are discontinuous and designated especially for the coals, requiring a high sample preparation and quantities of about few grams. These are some of the reasons that lead to the necessity for other tests, continuous, that will give the same results on the physical-chemical data with the same precision, analyzing wastes samples about some kilograms with a granulosity of centimeters, that don't require a preliminary laborious preparation.

\section{THE EXPERIMENTAL DEVICES}

\subsection{Installations description}

The installations used for this study are a tubular fix bed reactor (figure 1.a), external heated electrically for the discontinuous treatment and a vibro-fluidised bed thermal unit natural gas burner heated for the continuous treatment (figure 1.b).

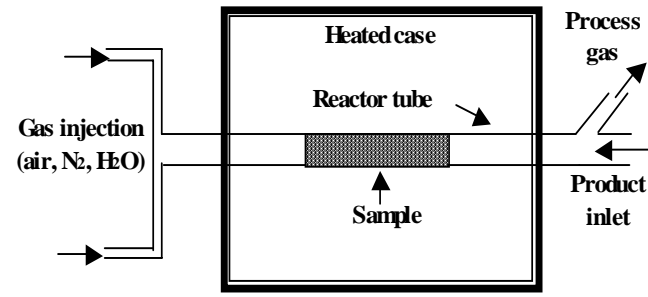

a) discontinuous treatment unit

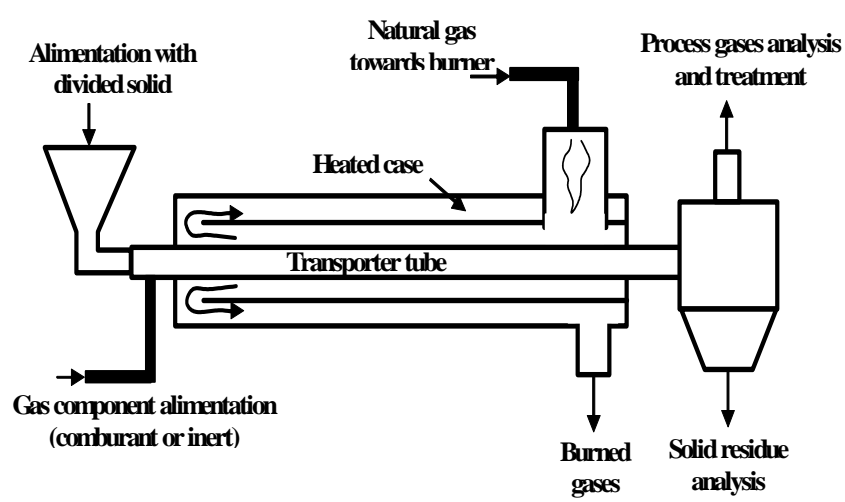

b) continuous treatment unit

Figure 1. The functional schema of the installations used for the MSW treatment.

The first laboratory scale reactor consists in an external heated tube within the inner diameter is of $34 \mathrm{~mm}$ and $500 \mathrm{~mm}$ long. The active zone, heated one, is about $300 \mathrm{~mm}$. The tube has two gas inlets for different experimental conditions: air, nitrogen or steam. The treated sample is introduced within a refractory steel tube. This device accepts quantities of about 3-10 grams for temperatures up to $1100^{\circ} \mathrm{C}$.

The industrial scale pilot used along this study was developed in the laboratory of University of Technology Compiègne, to quantify the hydrodynamics and heat exchanges in a vibrantfluidized bed thermal unit. It consists in a tubular rectilinear reactor heated by hot flue-gases circulation (natural gas burner) within an external double envelope. The solid advances continuously by vibro-fluidised transport. This type of transportation corresponds to a piston- 
like flow ${ }^{1}$. The advancing speed of solids is fixed by the installation vibratory parameters [2]. The tube inner diameter is $160 \mathrm{~mm}$ and $4000 \mathrm{~mm}$ long (the heated zone $3300 \mathrm{~mm}$ ). The flow rate (up to $50 \mathrm{~kg} \mathrm{~h}^{-1}$ ) is fixed by the feeding ratio together with advancing speed in the installation, and it imposes different filling levels of the tube. The unit operates at temperatures from 400 up to $1100^{\circ} \mathrm{C}$. The adjustable installation parameters for the divided solids transport inside the tube are: the vibration frequency, the impulse ${ }^{2}$, the tube inclination and the feed flow rate [3].

\subsection{The samples}

Compared to pyrolysis and gasification of wood or biomass, generally speaking, the presence of plastics, rubber and other high volatile components modify the reaction kinetics and the waste behavior during treatment. The reason we chose the MSW is its high heterogeneity degree and the important water content.

We used two types of reconstituted MSW depending on the installation. For the industrial scale unit the sample consists in 21 components: vegetal $-31.7 \%$; packages $-1.5 \%$; journals - 3\%; magazines - 4\%; other papers - 7.1\%; cardboard - 10\%; complex (aluminium+plastic+cardboard packages) $-1.5 \%$; textiles $-2.9 \%$; hygienically textiles $-3.5 \%$; polyolefin - 6.8\%; PET - 1.9; bottles polyolefin (house cleaning products) $-2 \%$; PVC $-0.6 \%$; polystyrene $-0.9 \%$; wood $-1 \%$; leather $-1.35 \%$; rubber (tires) $-1.35 \%$; glass $-7.5 \%$; Fe $3 \%$; Al $-0.8 \%$; brick $-3.8 \%$; concrete $-3.8 \%$. These components represents the MSW composition in France within the humidity is about $27.5 \%$ and the low calorific value about $8500 \mathrm{~kJ} \mathrm{~kg}^{-1}$ [4]. This large number of components can be achieved in the mixture because of the important quantities of product to be treated - up to $50 \mathrm{~kg} \mathrm{~h}^{-1}$ in the vibro-fluidized installation. With respect to the laboratory pilot, on the contrary, the quantities can't exceed 5 - 7 grams / experiment. Therefore, to reconstitute a 5 grams sample with 21 components is quasi - impossible due to measuring errors (the components mass fraction is comparable to the balance error) and components preparation procedure (limited granulosity due to wastes structure). To solve this problem we decreased the number of components from 21 to 9 . We grouped the components into 3 main classes: vegetal - 32\%, combustibles (paper - 20\%; cardboard - 11\%; plastic - 14\%; wood - 1.5\%; leather - 1.5\%) and inert (glass - 16\%; Fe $3 \% ; \mathrm{Al}-1 \%)$. The difference between these two reconstituted samples is minimal: $1 \%$ for the vegetal components, $2 \%$ for the combustible and $6 \%$ for the inert.

\section{RESULTS AND ANALYSIS}

\subsection{Operational procedure}

The main parameter that indicates the treatment efficiency is the mass reduction rate. Due to the product high heterogeneity this parameter is affected by the inert component mass fraction variation at the installation inlet. The laboratory experiments are not representative for the gases analysis because of the discontinuous treatment, when it is well known that the main cause of the pollutants instantaneous concentrations increase is the charged product quality and the load variation that requires a continuously operation unit. In the same time a discontinuous treatment applied to a precisely reconstituted MSW sample will provide accurate data on its mass reduction rate. Therefore we established a criterion called TRFC (Taux de Réduction de la Fraction Combustible) that quantifies the combustible fraction reduction. For a fixed residential time and operation temperature only a part of the combustible fraction of the waste is oxidized. Therefore this parameter is important to characterize the waste combustibility intrinsic properties.

$$
\text { TRFC }=\frac{\mathrm{X}_{\mathrm{m}}}{\mathrm{z}_{\mathrm{COMB}}^{\mathrm{S}}}[\%] \quad(1) \quad \mathrm{X}_{\mathrm{m}}\left(\mathrm{T}, \mathrm{t}_{\mathrm{s}}\right)=100 \times \frac{\dot{\mathrm{m}}_{\mathrm{m}}-\dot{\mathrm{m}}_{\mathrm{m}}^{\prime}}{\dot{\mathrm{m}}_{\mathrm{m}}} \quad[\%]
$$

with:

$z_{\text {comB }}$ - the combustible mass fraction of the waste; $x_{m}-$ the mass conversion rate (reduction) for fixed temperature and residential time; $T$ - the fixed temperature of the

\footnotetext{
${ }^{1}$ If we consider a transversal section in the solid advancing bed the particles distribution and number in this section will be same all along the transporter tube without the layers sliding.

${ }^{2}$ The vibration force.
} 
process; $t_{s}$ - the fixed residential time; $\dot{\mathrm{m}}_{\mathrm{m}}$ - the waste mass feed flow; $\dot{\mathrm{m}}_{\mathrm{m}}^{\prime}$ - the solid residues mass flow at the installation outlet.

As the waste has inert components and a combustible fraction as well, it is important to know not the global mass reduction rate but the mass reduction rate of its combustible fraction ${ }^{3}$, in order to establish the product reaction kinetics [5]. The equation (3) connects the TRFC of collected solid residues with the un-oxidized fraction $X_{\mathrm{IMB}}$ in the slag:

$\mathrm{TRFC}=\frac{100}{\mathrm{z}_{\mathrm{COMB}}^{\mathrm{S}}} \times\left[\mathrm{z}_{\mathrm{COMB}}^{\mathrm{S}}-\mathrm{X}_{\mathrm{IMB}} \frac{\mathrm{z}_{\mathrm{IN}}^{\mathrm{S}}}{100-\mathrm{X}_{\mathrm{IMB}}}\right][\%]$

with:

$\mathrm{Z}_{\mathrm{IN}}^{\mathrm{S}}$ - inert mass participation in the waste; $\mathrm{X}_{\mathrm{IMB}}$ - un-oxidized fraction in the slag.

The experiments for the mass reduction rate were performed in the laboratory tubular reactor at different temperatures $\left(500^{\circ} \mathrm{C}, 650^{\circ} \mathrm{C}, 800^{\circ} \mathrm{C}\right)$ for pyrolysis conditions $\left(\mathrm{N}_{2}\right.$ atmosphere $)$ and at $950^{\circ} \mathrm{C}$ in incineration.

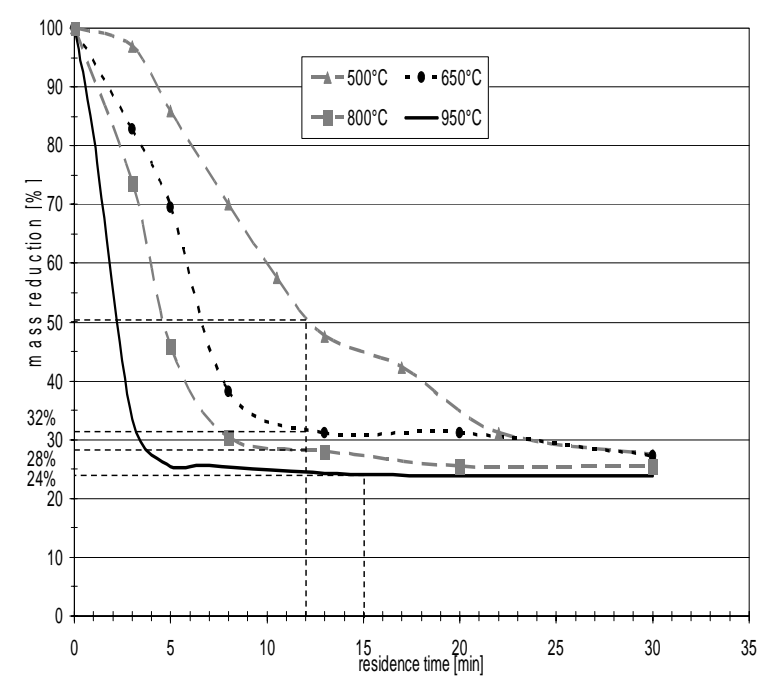

a)

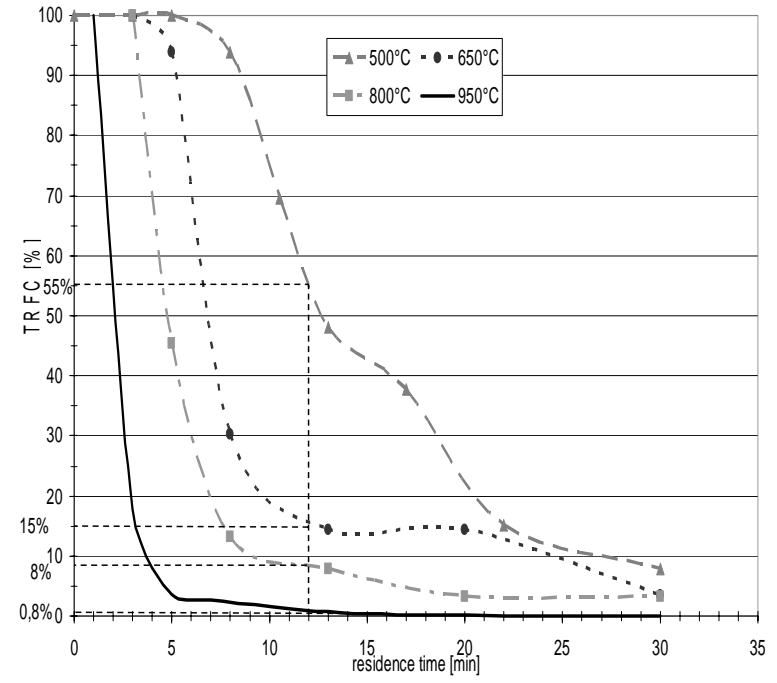

b)

Figure 2. The MSW sample mass variation during pyrolysis $\left(500-800^{\circ} \mathrm{C}\right)$ and incineration $\left(950^{\circ} \mathrm{C}\right)$ for different residential time

Figure 2. shows the mass reduction variation (a) and the combustible fraction variation, TRFC, (b) for different constant temperatures and different residential time. In the figure 2.b the horizontal zone at 100\% corresponds to the drying period, from 1 up to 5 minutes followed by the devolatilisation process represented by the fast variation of the sample mass. The temperature accelerates the mass reduction but for an infinite treatment period the difference between the variation curves reduces. The curves show the difference that residential time makes between low temperature and high temperature pyrolysis. Thus, at $800^{\circ} \mathrm{C}$, the process is almost finished after $10-12$ minutes but at $500^{\circ} \mathrm{C}$ the period required for the same mass decrease is about 30 minutes. We also notice that even if the $650^{\circ} \mathrm{C}$ level is situated in the middle of the temperature range $500^{\circ} \mathrm{C}-800^{\circ} \mathrm{C}$ the variation curve follows closely the higher temperature shape. This can be explained by the fixed carbon behavior that begins to be liberated starting with $500^{\circ} \mathrm{C}$ [6]. So we expect the pyrolysis char at $650^{\circ} \mathrm{C}$ to be similar to the one obtained at $800^{\circ} \mathrm{C}$.

The incineration curve, the lower one on the diagram is represented as a reference for the mass variation speed. Passing to the pilot installation and accomplishing four series

\footnotetext{
${ }^{3}$ The un-combustioned fraction $X_{I M B}$ in the slag will be taken into consideration.
} 
of tests at the same temperatures for a residential time equal to 12 minutes we obtained the data in the table 1 (average values).

Table 1. The mass conversion and gases components in pyrolysis and incineration tests

\begin{tabular}{|c|c|c|c|c|c|c|c|}
\hline \multirow{3}{*}{ Parameters } & \multicolumn{6}{|c|}{ Pyrolysis } & \multirow{3}{*}{\begin{tabular}{|c|} 
Incineration \\
$950^{\circ} \mathrm{C}$ \\
Pilot \\
\end{tabular}} \\
\hline & \multicolumn{2}{|c|}{$500^{\circ} \mathrm{C}$} & \multicolumn{2}{|c|}{$650^{\circ} \mathrm{C}$} & \multicolumn{2}{|c|}{$800^{\circ} \mathrm{C}$} & \\
\hline & Pilot & Lab & Pilot & Lab & Pilot & Lab & \\
\hline $\mathrm{X}_{\mathrm{m}}$ & $65.90 \%$ & $31.75 \%$ & $59.70 \%$ & $59.98 \%$ & $69.30 \%$ & $64.92 \%$ & $70.00 \%$ \\
\hline $100-X_{\text {IMB }}$ & $77.00 \%$ & $43.14 \%$ & $78.60 \%$ & $73.56 \%$ & $79.00 \%$ & $83.91 \%$ & $98.12 \%$ \\
\hline $\mathrm{O}_{2}[\%]$ & 1 & - & 2.3 & - & 2.8 & - & 9.5 \\
\hline $\mathrm{CO}_{2}[\%]$ & 13 & - & 12 & - & 10 & - & 20 \\
\hline $\mathrm{CO}$ [ppm] & $>5000$ & - & $>5000$ & - & $>5000$ & - & 130 \\
\hline NOx [ppm] & 30 & - & 28 & - & 16 & - & 115 \\
\hline $\mathrm{SO}_{2}[\mathrm{ppm}]$ & 150 & - & 270 & - & 300 & - & 2 \\
\hline Gas LHW & \multicolumn{2}{|c|}{$4400 \mathrm{~kJ} \mathrm{Nm}^{-3}$} & \multicolumn{2}{|c|}{$8030 \mathrm{~kJ} \mathrm{Nm}^{-3}$} & \multicolumn{2}{|c|}{$8230 \mathrm{~kJ} \mathrm{Nm}^{-3}$} & - \\
\hline
\end{tabular}

The waste mass flow was about $3 \mathrm{~kg} \mathrm{~h}^{-1}$. We notice the similitude of the data on the mass conversion between the two treatments, in laboratory and on the vibro-fluidized pilot. For the test at $500^{\circ} \mathrm{C}$ the big difference of about $47 \%(65.9 \%$ versus $31.75 \%)$ is related to the isothermal profile of the pilot installation affected by the low temperature level. Thus, the temperature profile decreases to the installation inlet. The low temperature in the feeding system zone modifies the waste mechanical behavior: The plastics components need a longer period to volatilize therefore the melting process becomes important causing a delay on the waste advancement. So, the residential time is longer, up to 20-23 minutes. If we compare the pilot mass conversion rate of $65.9 \%$ to the laboratory one in the figure 2 . corresponding to a residential time of 24 minutes we find the same $65 \%$ mass conversion rate. The pyrolysis kinetics at $650^{\circ} \mathrm{C}$ is similar to $800^{\circ} \mathrm{C}$ one. Concerning the liberated gases we noticed that the participation of $\mathrm{H}_{2}, \mathrm{CO}$ and $\mathrm{CH}_{4}$ increases at higher temperature having a faster variation in the first 2 minutes, but the $\mathrm{CO}_{2}$ is constant depending only on the $\mathrm{O}_{2}$ concentration. The hydrogen production increases 18 times from $0.0003 \mathrm{~mol}$ to $0.0055 \mathrm{~mol}$ $\mathrm{gr}^{-1}$ of waste.

For the gasification process we used the char from the MSW pyrolysis at $500^{\circ} \mathrm{C}$ and $650^{\circ} \mathrm{C}$. The operation conditions were: temperature -800 and $1000^{\circ} \mathrm{C}$; steam flow -1 to $3 \mathrm{gr} \mathrm{min}^{-1}$ for 5 grams of MSW. The fixed carbon in the char obtained at $500^{\circ} \mathrm{C}$ is practically double compared to the other sample. Will not insist on the temperature influence on the gases production, obviously sensitive higher at $1000^{\circ} \mathrm{C}$ but on the steam flow. Figure 3. presents the steam mass flow influence on the gas production at $1000^{\circ} \mathrm{C}$ in $\mathrm{mol} \mathrm{gr}^{-1}$ of waste. The amount of $\mathrm{H}_{2}$ is for 2.2 times higher when using a triple quantity of steam. In the same time the $\mathrm{CO}$ and $\mathrm{CO}_{2}$ quantity increases four times.

Furthermore the reaction speed increases, the period to reach the steady state being reduced with about 10 minutes. The combustible waste fraction mass conversion rate varies from $95 \%$ to $100 \%$ due to the steam flow increase.

\section{CONCLUSIONS}

The pilot installation gives the possibility to establish the wastes in mixtures thermo-chemical properties in combustion, pyrolysis or gasification conditions. The solid waste submits a continuously homogenous thermal treatment process, guaranteed by the unit isothermal profile and the piston-like flow residential time distribution. The continuous treatment insures an accurate dynamic process gas analysis. The mass variation rate was validated by laboratory test in discontinuous treatment. The MSW pyrolysis at $650^{\circ} \mathrm{C}$ is similar to $800^{\circ} \mathrm{C}$ with respect to the mass variation and gases formation kinetics. The temperature augmentation accelerates the gasification process and the $\mathrm{CO}+\mathrm{H}_{2}$ production at atmospheric pressure treatment conditions. The increase of the steam mass flow accelerates the char conversion speed with about $40 \%$ as well the gas production, therefore the interest 
of operating with a steam / waste char ratio about $0.6(\approx 2.6$ if we exclude the inert char content) at $900-1000^{\circ} \mathrm{C}$ and atmospheric pressure.

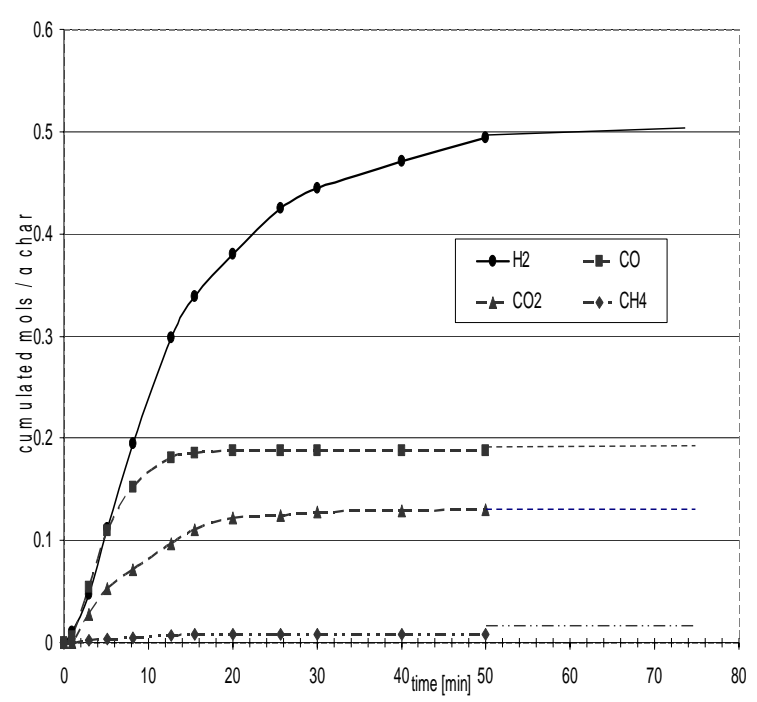

a) steam mass flow - $1 \mathrm{~g} \mathrm{~min}^{-1}$

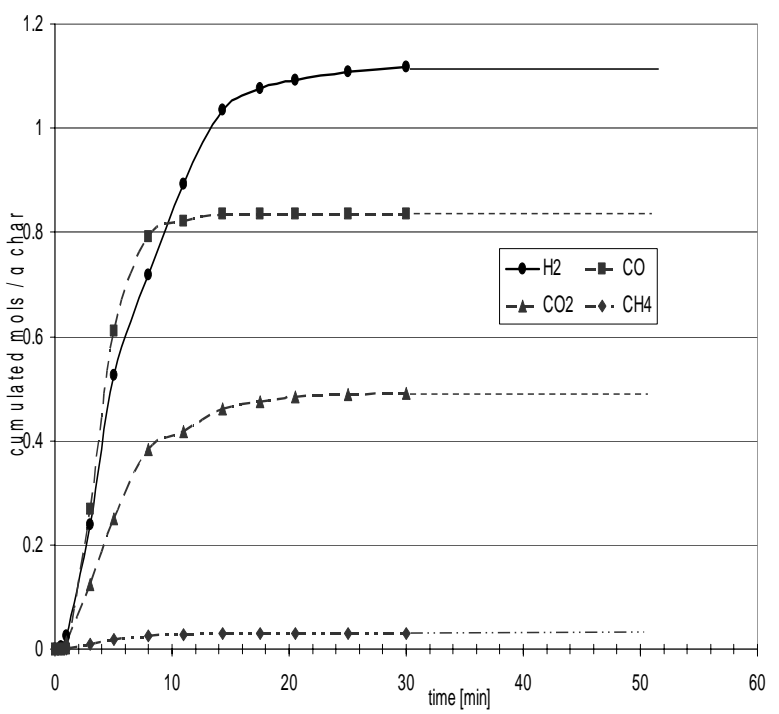

b) steam mass flow $-3 \mathrm{~g} \mathrm{~min}{ }^{-1}$

Figure 3. $\mathrm{MSW} 650^{\circ} \mathrm{C}$ pyrolysis char steam gasification at $1000^{\circ} \mathrm{C}$

\section{REFERENCES}

1. Tillman D.A. (1991) The combustion of solid fuels and wastes, Academic Press, INC., Boston.

2. Caudron J.C. (1999) The set up of a procedure for the solid wastes incinerability characterization, Ph.D. Thesis, Compiègne University of Technology, France.

3. Nagaiev R.F. (1978) Periodic regimes of vibrational transport, Nauka Press.

4. Marculescu C. and Bouillon P.A. (2004) Evaluation multicritère comparative des modes de traitements thermiques alternatifs à l'incinération des déchets, Raport ADEME (National Agency Energy Environment).

5. Martin C. (2001) Modelisation and combustion criterion of the combined urban and common industrial wastes incineration, Ph.D. thesis, Compiègne University of Technology, France.

6. Rath J. and Staudinger G. (2001) Craking Reactions of Tar from Pyrolysis of Spruce Wood, Fuel, 80, 1379-1389. 